\title{
Low semen quality and adverse histological changes in testes of adult male mice treated with bee venom (Apis mellifera)
}

\author{
Sassia O. Regeai ${ }^{1,2 *}$, Salma A. Abusrer ${ }^{2}$ and Naema S. Shibani ${ }^{1,2}$ \\ ${ }^{1}$ Department of Life Sciences, School of Basic Science, Libyan Academy of Postgraduate Studies, Janzour, Libya \\ ${ }^{2}$ Zoology Department, Faculty of Science, University of Tripoli, Tripoli, Libya
}

\begin{abstract}
Background: Male infertility has been on the rise since the past seven decades. Recently, in Libya, bee venom therapy (BVT) has become a popular method among alternative healthcare practitioners for treating male infertility. However, a literature search did not find any published studies that investigated the use of BVT for infertility treatment.

Aim: To investigate the effect of bee venom on the male reproductive status through measurements of semen quality parameters and testicular histological changes in adult male mice.

Methods: A total of 48 male mice were randomly divided into three experimental groups (which were subdivided into two subgroups with eight mice each) as follows: control, bee venom sting (BVS), and bee venom injection (BVI). The normal control subgroup mice were not subjected to any treatment, while the vehicle control subgroup mice were injected (i.p.) with $200 \mu \mathrm{l}$ of $0.9 \%$ saline solution. In the BVS-treated subgroups, each mouse was stung by one live bee for five times (BVS-5) or seven times (BVS-7) every third day for 2 or 3 weeks. While each mouse in the BVI-treated subgroups received $23 \mu \mathrm{g} / \mathrm{kg}$ in a dose volume of $200 \mu$ l BVIs (i.p.) for five times (BVI-5) or seven times (BVI-7) every third day for 15 or 21 days.

Results: The findings of this study showed that repeated bee venom treatment by sting or injection to adult male mice resulted in a significant decline in testosterone levels, sperm count, sperm motility, and a very significant increase in the percentage of abnormal sperm morphology; also, there were harmful testicular histological changes in the structural organization of seminiferous tubules and degenerative changes in the germinal epithelium compared to control group. Conclusion: The results of this study provide evidence for the low semen quality and adverse testicular histological changes in male mice treated with bee venom. Hence, there is a desperate need for educating alternative healthcare practitioners and infertile couples about the harmful effects of BVT on reproductive status.

Keywords: Bee venom, Complementary and alternative medicine, Libya, Mouse testes, Semen quality.
\end{abstract}

\section{Introduction}

Infertility is a disease of the reproductive system, especially the gamete producing organs: testes and ovaries (Zegers-Hochschild et al., 2009; WHO, 2014; Sun et al., 2019), defined by the inability to achieve pregnancy within 1 year of marriage without the use of contraceptives (WHO, 2014). About $8 \%-15 \%$ of married people in the world suffer from infertility (Ombelet and Onofre, 2019; Sun et al., 2019). Environmental and genetic factors, as well as a variety of lifestyle choices, have been associated with infertility. Clinical studies show that the male and female causes of infertility are approximately equal (Irvine, 1998; Sadeghi, 2020). The last three decades has witnessed a worldwide increase in infertility, from 1990 to 2017 (Sun et al., 2019). Furthermore, male infertility has been on the rise since the mid-1950s (Carlsen et al., 1992; Auger et al., 1995; de Kretser, 1997; Agarwal et al., 2015; Sengupta et al., 2017, 2018; Sun et al., 2019). Infertility is emerging as a growing major global reproductive health problem (WHO, 2015; Baskaran et al., 2019; Sun et al., 2019; Sadeghi, 2020). The procedures of diagnostics and treatment of infertility are long term, complicated, highly expensive, and do not always end successfully (Inhorn and Patrizio, 2015; Kissin et al., 2016; Dukhovny et al., 2018). Therefore, many infertile couples seek complementary and alternative medicines (CAM) for infertility treatment (Smith et al., 2010; Frass et al., 2012; Ghazeeri et al., 2012; Bardaweel et al., 2013; Read et al., 2014; Hwang et al., 2019) to improve their chances of having a child. The most common CAM methods for infertility treatments include religious healing, meditation, acupuncture, and herbal therapy (O'Reilly et al., 2014; Read et al., 2014; Miner et al., 2018).

In Libya, there is a lack of information about the causes, diagnosis, and overall prevalence of infertility among the population (Eldib and Tashani, 2018; Teka, 2018). Childlessness is a big issue in the Libyan society; hence, many couples turn to alternative traditional medicine for treatment due to the low income, high cost, and sometimes unsuccessful outcome of various assisted reproductive technologies (ART). In addition, infertility care is not included in the public health system of Libya 
and there are only about 10 private ART clinics (Inhorn and Patrizio, 2015). The use of traditional medicine in Libya dates back to a long time in history (Kotb, 1985; El-Mokasabi, 2014; Ashur et al., 2017). The number of CAM clinics, in Libya, has increased significantly over the last decade. Nutritional supplements (e.g., nuts, honey, royal jelly), herbs (e.g., fenugreek, olibanum, black seeds, rosemary, thyme), and spiritual practices (e.g., wet cupping and supplications) are among the most commonly used methods by Libyan CAM healthcare practitioners. Recently, BVT has become a widely used practice among alternative healthcare practitioners in Libya to treat male infertility.

BVT is a natural treatment for inflammation and pain using live bee stings or injections of purified and diluted bee venom (Zhang et al., 2018). It has been practiced by the ancient Greeks, Chinese, and Egyptians to treat many diseases such as osteoarthritis, rheumatoid arthritis, fatigue, and skin diseases (Ali, 2012; Wehbe et al., 2019). Bee venom contains various proteins, peptides, enzymes, and neurotransmitters which include melittin (Mlt), apamin, adolapin, histamine, the mast cell degranulating peptide, phospholipase A, hyaluronidase, dopamine, and serotonin (Wehbe et al., 2019; Aufschnaiter et al., 2020). Bee venom has a variety of pharmaceutical properties including analgesic (Li et al., 2015), anticancer (ElBassiony et al., 2016), antibacterial (Han et al., 2016; Zolfagharian et al., 2016), antifungal (Yu et al., 2012; Park et al., 2018), antiviral (Uddin et al., 2016), neuroprotective (Ye et al., 2016), and the treatment of many skin conditions (Kim et al., 2019). However, only two published studies had investigated the potential toxic effects of bee venom on testicular tissue (Florea et al., 2017; Tilinca and Florea, 2018) and none on semen quality parameters (i.e., sperm analyses). Hence, there is a lack of reproductive toxicological studies which evaluate the impact of bee venom exposure on the male reproductive function and semen quality. The evaluation of male reproductive status depends on the measurements of sperm parameters, which include sperm count, sperm motility, sperm viability, and sperm morphology (Trivedi et al., 2010). Therefore, the aim of this study was to investigate the effect of bee venom on the male reproductive status through measurements of sperm parameters and testicular histological changes in adult male mice by direct bee venom stings (BVSs) and diluted bee venom injections (BVIs).

\section{Material and Methods}

\section{Bee venom}

Forager honeybees Apis mellifera (order Hymenoptera, family Apidae) used in this study were collected from colonies of natural honeybees maintained at the Faculty of Agriculture, University of Tripoli, Libya. The bees were collected in the morning and kept in aerated glass jars and were used on the same day to sting the mice, once every third day for 15 (five doses) or 21 (seven doses) days. A forager honeybee contains about $150 \mu \mathrm{g}$ of venom (Schumacher et al., 1994), and it can inject 30-100 $\mu \mathrm{g}$ of venom via its stinger (Ali, 2012).

Lypholized A. mellifera (order Hymenoptera, family Apidae) purified bee venom was supplied by Al-Hart CAM clinic who purchased it from VACSERA, Egypt. Lyophilized bee venom was dissolved in saline solution $(0.9 \% \mathrm{NaCl})$ for the preparation of the concentrations required in the experiment and kept in the refrigerator at $4^{\circ} \mathrm{C}$ until used. It was injected intraperitoneally (i.p) in the dose of $23 \mu \mathrm{g} / \mathrm{kg}$ body weight in a dose volume of $200 \mu$ once every third day for 15 (five doses) or 21 (seven doses) days.

The bee venom doses used in this study were extrapolated and calculated based on the human applied doses as practiced by the traditional healthcare practitioners in some Libyan CAM clinics.

\section{Animals}

Adult male Swiss albino mice, 6-8 weeks old and weighing 25-30 g, were used in this study. These mice were obtained from the animal house of the Zoology Department, Faculty of Science, University of Tripoli. Polycarbonate cages with bedded wood shavings and steel wire tops were used to house four mice per cage. Mice were kept under appropriate conditions and allowed free access to food and water. Mice's body weights were measured using a digital balance before bee venom treatment and before sacrificing the mice.

\section{Experimental design}

48 adult male mice were equally divided into three experimental groups, with 16 mice per group. These groups were further subdivided into two subgroups with eight mice each. Group I: control, normal control and vehicle control. Group II: BVS-treated group, five dose BVS-5 subgroup and seven dose BVS-7 subgroup. Group III: BVI-treated group, five dose BVI-5 subgroup and seven dose BVI-7 subgroup. The normal control mice were not subjected to any treatment, while the vehicle control mice were injected (i.p.) with $200 \mu \mathrm{l}$ of $0.9 \%$ saline solution. In the BVS-treated subgroups, each mouse was stung by one live bee for five times (BVS-5) or seven times (BVS-7) every third day for 2 or 3 weeks. While each mouse in the BVI-treated subgroups received $23 \mu \mathrm{g} / \mathrm{kg}$ in a dose volume of 200 $\mu 1$ BVIs (i.p.) for five times (BVI-5) or seven times (BVI-7) every third day for 15 or 21 days.

The mice were sacrificed after 3 days of the last bee venom treatment (i.e., on day 18 for the five dose subgroups, and on day 24 for the seven dose subgroups). The mice were anaesthetized with chloroform inhalation, the abdominal cavity was opened, and a cardiac puncture was carried out to obtain blood samples from the heart to determine serum testosterone hormone levels. The animals were then scarified by cervical dislocation and the epididymis was collected and placed in normal saline for sperm analyses and evaluation (sperm count, sperm motility, and sperm morphology), as well as the testes for histological examination. 


\section{Determination of serum testosterone levels}

Testosterone levels were determined by enzyme-linked immunosorbent assay commercial kit, following the procedures outlined by the manufacturer (BioChek). Clotted blood samples were centrifuged for 15 minutes at 3,000 rpm to separate the serum and were stored at $-20^{\circ} \mathrm{C}$ until measurement of testosterone hormone.

\section{Determination of sperm parameters}

\section{Sperm count}

Sperm count was determined as described by Yokoi et al. (2003) using an improved Neubauer hemocytometer. Epididymal spermatozoa were collected in $1 \mathrm{ml}$ of normal saline into a clean Petri dish, mixed thoroughly, and incubated at $37^{\circ} \mathrm{C}$ for 5 minutes to separate the spermatozoa in the sperm suspension. After dilution, approximately $100 \mu \mathrm{l}$ of sperm suspension was loaded onto the hemocytometer to count the spermatozoa under a light microscope at a $400 \times$ magnification. Sperm count values were multiplied by the dilution factor and recorded as millions per milliliter $\left(10^{6} / \mathrm{ml}\right)$.

\section{Sperm motility}

The percentage of sperm motility was microscopically evaluated adopting Fiscor and Ginsberg's (1980) method. A drop of diluted sperm suspension was loaded onto the Neubauer hemocytometer and the number of motile and non-motile sperms was counted under a $400 \times$ magnification. The number of motile and nonmotile spermatozoa was expressed as percentage from the total number of counted spermatozoa.

\section{Sperm morphology}

The assessment of sperm morphological abnormalities was carried out by making two sperm smears from each mouse. The smears were stained with $1 \%$ eosin $\mathrm{Y}$ in water for 10 minutes, air-dried, and coded. Subsequently, at least 500 sperms from each mouse were examined under the microscope for the presence of any sperm morphological abnormalities. The determined sperm morphological abnormalities were expressed as percentage. The criteria for abnormal sperm morphology included tail and head abnormalities.

\section{Testes histopathological examination}

The testes were removed from bee venom-treated and control mice for histological examination. Testes were fixed in $10 \%$ buffered formalin and processed for routine hematoxylin and eosin (H\&E) staining. In each experimental group, three histology slides from three different mice were examined for signs of testicular damage, which included the following histopathological alterations: peritubular tissue changes, detachment of germ cells (spermatogonia) from the basement membrane of seminiferious tubules, sloughing (degeneration) of germ cells into the lumen of the seminiferous tubule, vacuolization (empty spaces) in the germinal epithelium of seminiferious tubules and Sertoli cells, and organization and width of seminiferious tubules. In addition, a comparative quantitative histopathological evaluation of the testis was conducted. For each experimental group, the average percentage of damaged seminiferous tubules was determined. By counting the total number of rounded tubules in a randomly microscopic field, the average percentage of damaged seminiferous tubules was calculated by dividing the number of round tubules with a histopathological sign (i.e., detachment, sloughing, and vacuolization) by the total number of round tubules in the same field multiplied by 100 . The mean of three randomly microscopic fields per animal for each slide was considered.

\section{Statistical analysis}

Body weights and semen quality values: sperm count, sperm motility, sperm morphology, and testosterone levels were recorded as mean \pm standard deviation (SD) and were analyzed by one-way analysis of variance using MSTATE-C version 4 software. Duncan's test with a p-value of $<0.05$ was considered statistically significant between the control and the bee venomtreated groups.

\section{Ethical approval}

All experiments in this study complied with the bioethical research established by the Libyan National Committee for Biosafety and Bioethics; and its methodology conforms to the published guide "Principles of laboratory animal care" [NIH (National Institute of Health), 1985].

\section{Results}

Apis mellifera bee venom had an adverse toxic effect on the testosterone levels and on all sperm analyses: sperm count, sperm motility, and normal sperm morphology, analyzed in this study; also, there were harmful testicular histological changes. However, normal and vehicle control subgroups showed normal sperm parameters and testicular tissue. In addition, there was no significant body weight difference between the control and bee venom-treated mice (Table 1).

\section{The effect of bee venom on semen analyses}

There was a significant reduction in sperm count of mice treated with bee venom $(p \leq 0.05)$. The lowest sperm count was observed in BVI-5 $\left(6.6 \pm 2.8 \times 10^{6}\right)$ and BVS-5 $\left(7.2 \pm 6.5 \times 10^{6}\right)$ in comparison with the normal control group $\left(25.8 \pm 0.9 \times 10^{6}\right)$ (Table 1$)$. Reduction in sperm count was accompanied by low levels of testosterone hormone in the bee venom-treated mice. Testosterone levels were significantly reduced $(p$ $<0.001)$ in BVS-5 $(0.17 \pm 0.1 \mathrm{ng} / \mathrm{ml})$ and BVI-5 $(0.15$ $\pm 0.1 \mathrm{ng} / \mathrm{ml})$, as well as BVS-7 (0.79 \pm 0.7$)$ and BVI-7 $(1.20 \mathrm{ng} / \mathrm{ml})$ when compared to normal control $(2.41$ $\pm 0.7 \mathrm{ng} / \mathrm{ml}$ ) (Table 1). However, the BVS-7 and BVI7 subgroups showed a slight increase in sperm count $\left(12.2 \pm 0.9 \times 10^{6}\right.$ and $10.9 \pm 2.9 \times 10^{6}$, respectively) and testosterone levels in comparison to BVS-5 and BVI-5 (Table 1), which is an indication of some recovery in spermatogenesis. In addition, about a $50 \%$ decline in the mean percentage of motile sperms of bee venomtreated mice was observed (Table 1). The lowest sperm 
motility was observed in the BVI-7 subgroup (49.6 \pm 13.5) verses control $(95.1 \pm 2.6)$ group (Table 1$)$.

The most adverse toxic effect of bee venom was observed on sperm morphology considering the highly significant $(p \leq 0.001)$ decrease in the mean percentage of normal sperm morphology of all bee venom-treated mice (range: $2.70 \pm 2.0 \%-$ $5.30 \pm 10 \%)$ verses control $(86.5 \% \pm 11 \%)$ group (Table 1). The most common morphological sperm tail abnormalities were bent tail, coiled tail, and ring tail; head abnormalities included amorphous head, forked head, and hookless head (Fig. 1).

\section{The effect of bee venom on testicular histopathology}

Gross anatomical examination of the testes showed a significant enlargement of the testis size in most bee venom-treated groups (Fig. 2), due to edema. In general, histological slides of testes in the normal and vehicle control subgroups showed a normal histological structure of the testis, normal pattern of seminiferous tubules of uniform size lined by several layers of orderly arranged germinal epithelial cells (spermatogonia), narrow lumen with high spermatozoa concentration, presence of supportive cells (Sertoli cells), little interstitial space with normal interstitial cells (Leydig cells), and few macrophages (Fig. 3). Few histopathological alternations in the testicular sections from control mice were observed; the percentage of damaged seminiferous tubules was approximately $2 \%$ (Table 1).

However, histological sections prepared from the testes of bee venom-treated subgroups revealed distorted testicular tissue with marked damage in the histoarchitecture of seminiferous tubules and degenerative changes in germinal epithelium (Figs. 4 and 5) compared to the control group (Fig. 3). In general, the seminiferous tubules were disorganized showing detachment of germ cells and Sertoli cells (i.e., partition of cells from the basement membrane of

Table 1. Mean value ( \pm SD) of sperm count, sperm motility, normal sperm morphology, damaged seminiferous tubules, testosterone hormone level, and body weight of control and bee venom-treated mice.

\begin{tabular}{cccccccc}
\hline $\begin{array}{c}\text { Experimental } \\
\text { groups }\end{array}$ & $\begin{array}{c}\text { Sperm count } \\
(\mathbf{1 0} / \mathbf{m l})\end{array}$ & $\begin{array}{c}\text { Sperm } \\
\text { motility (\%) }\end{array}$ & $\begin{array}{c}\text { Sperm } \\
\text { morphology (\%) }\end{array}$ & $\begin{array}{c}\text { Damaged } \\
\text { seminiferous } \\
\text { tubules (\%) }\end{array}$ & $\begin{array}{c}\text { Hormone } \\
\text { level } \\
\mathbf{( n g / m l )}\end{array}$ & $\begin{array}{c}\text { Body weight (gm) } \\
\text { Before } \\
\text { treatment }\end{array}$ & $\begin{array}{c}\text { After } \\
\text { treatment }\end{array}$ \\
\hline Normal control & $25.8 \pm 0.9$ & $95.1 \pm 2.6$ & $86.5 \pm 11$ & $1.7 \pm 1.2$ & $2.41 \pm 0.7$ & $28.5 \pm 0.8$ & $29.5 \pm 1.1$ \\
Vehicle control & $23.6 \pm 5.0$ & $92.7 \pm 1.7$ & $84.7 \pm 18$ & $2.1 \pm 0.5$ & $2.53 \pm 1.2$ & $29.0 \pm 1.0$ & $31.0 \pm 1.0$ \\
BVS-5 & $7.2 \pm 6.5^{* *}$ & $55.5 \pm 17.1^{*}$ & $4.8 \pm 4.0^{* *}$ & $54.6 \pm 4.3^{* *}$ & $0.17 \pm 0.1^{* *}$ & $27.0 \pm 1.3$ & $27.3 \pm 3.2$ \\
BVS-7 & $12.2 \pm 0.9^{*}$ & $50.7 \pm 12.1^{*}$ & $3.60 \pm 3.2 * *$ & $26.7 \pm 2.6^{*}$ & $0.79 \pm 0.7 *$ & $28.1 \pm 1.5$ & $27.1 \pm 3.7$ \\
BVI-5 & $6.6 \pm 2.8^{* *}$ & $52.5 \pm 10.2^{*}$ & $5.30 \pm 10^{* *}$ & $59.8 \pm 5.6^{* *}$ & $0.15 \pm 0.1^{* *}$ & $29.8 \pm 1.5$ & $31.5 \pm 2.3$ \\
BVI-7 & $10.9 \pm 2.9^{*}$ & $49.6 \pm 13.5^{*}$ & $2.70 \pm 2.0^{* *}$ & $29.3 \pm 3.1^{*}$ & $1.20 \pm 0.9^{*}$ & $29.1 \pm 1.6$ & $31.4 \pm 2.0$ \\
\hline
\end{tabular}

Vertical values with $*(p \leq 0.05)$ and $* *(p \leq 0.001)$ were considered to be statistically significant between the control and bee venom-treated groups.

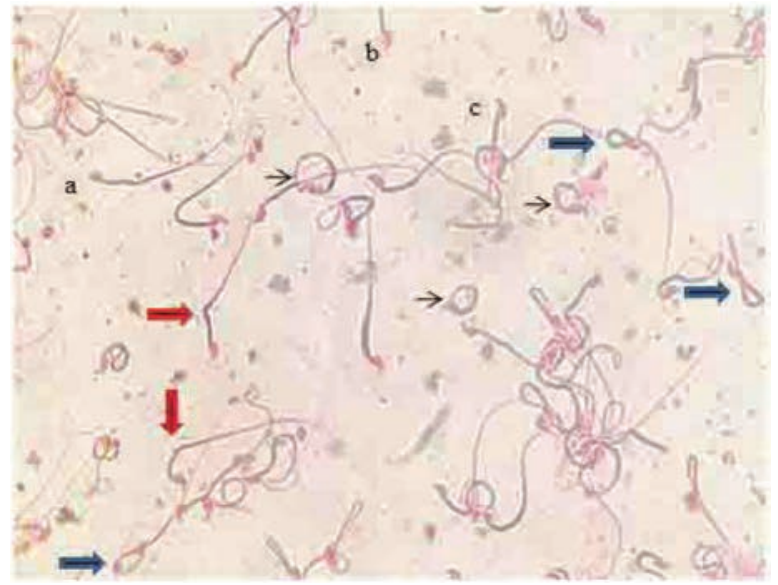

Fig. 1. Sperm smear (1.0\% eosin stain) of bee venom-treated mice showing tail and head sperm abnormalities: bent tail (red arrows), coiled tail (blue arrows), and ring tail (black arrows), amorphous head (a), forked head (b), and hookless head (c) $(400 \times)$.

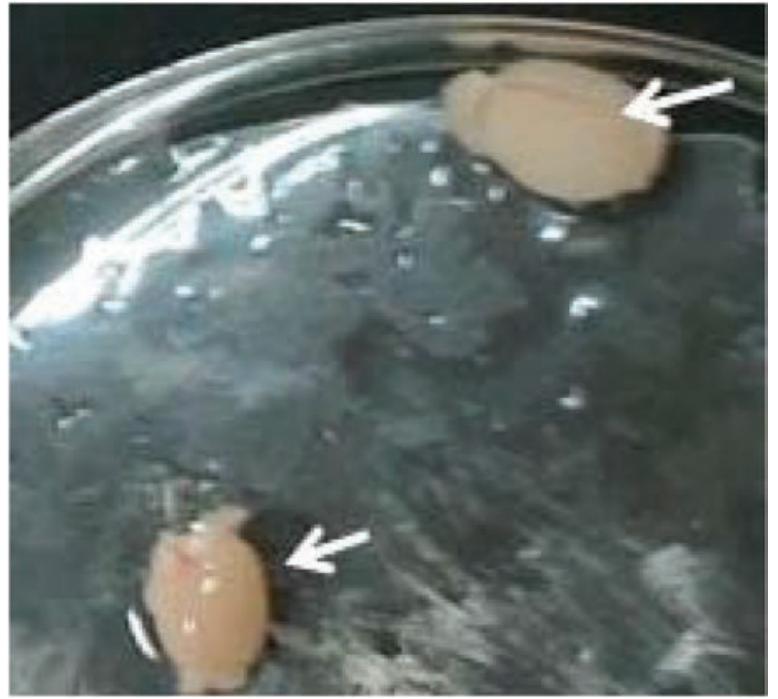

Fig. 2. Testis enlargement in the bee venom-treated mice compared to control. 


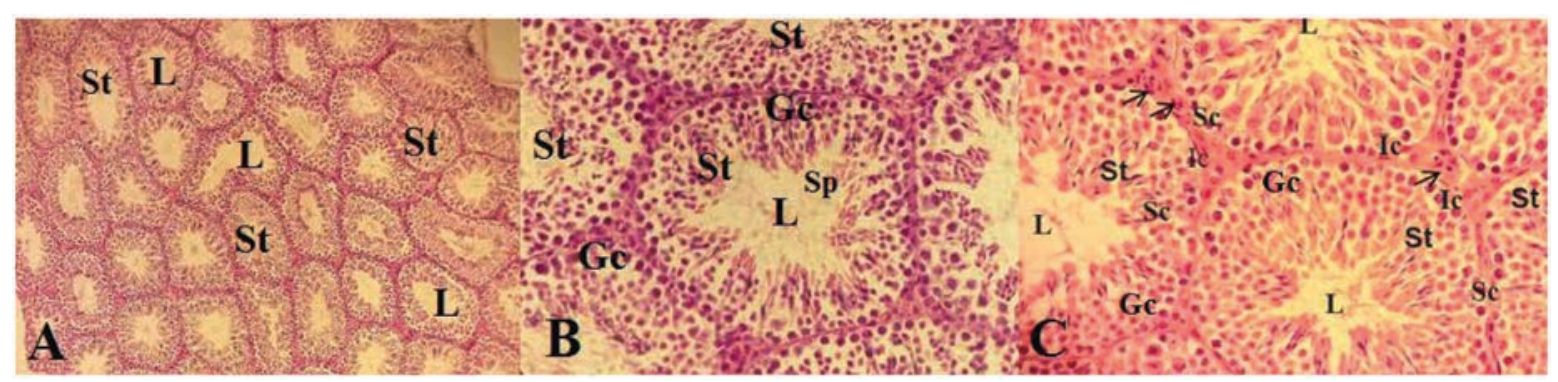

Fig. 3. Histological sections of testes in male mice of the control group showing normal patterns of seminiferous tubules (St) narrow lumen (L) with many spermatozoa (Sp), orderly organized germ cells (Gc), Sertoli cells (Sc), Leydig interstitial cells (Ic), normal presence of mononuclear cells (arrows), and little interstitial space (H\&E) (A: 200×) (B and C: 400×).

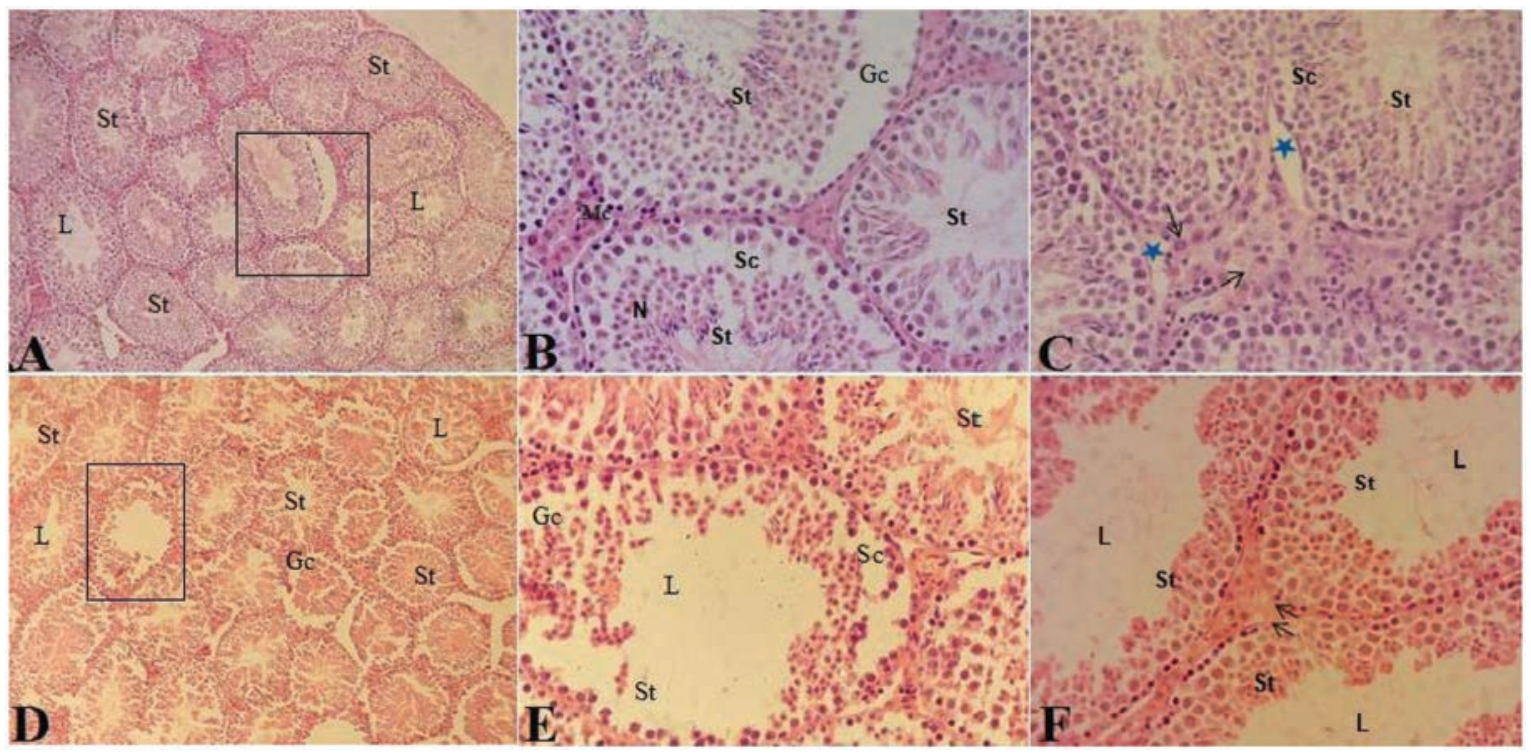

Fig. 4. Histological sections of testes in male mice treated with five doses of bee venom: BVS-5 subgroup (A, B, and C) and BVI-5 subgroup (D, E, and F) showing disorganized seminiferous tubules ( $\mathrm{St}$ ), vacuolization of seminiferous tubules, and increased interstitial space (A and D); sloughing of epithelial germ cells (Gc) and Sertoli cells (Sc), necrosis (N), and increased number of mononuclear cells $(\mathrm{Mc})(\mathrm{B}, \mathrm{C}$, and $\mathrm{E})$; edema (star) and hypertrophic Leydig interstitial cell with vacuoles (arrows) (C and F); dramatic decrease in spermatozoa and wide lumen (E and F) (H\&E) (A and D: 200×) (B, C, E, and F: 400×).

seminiferous tubule), sloughing of germinal epithelial cells (i.e., release of clusters of germ cells into the lumen of the seminiferous tubule), vacuolization (i.e., (appearance of empty spaces in the seminiferous tubules), reduction in sperm bundles within the lumen, and increased interstitial space in both the five dose (BVS-5 and BVI-5) and seven dose (BVS-7 and BVI7) bee venom-treated subgroups (Figs. 4 and 5). With regard to the quantitative histopathological evaluation, the five dose (BVS-5 and BVI-5) bee venom-treated subgroups showed the highest percentage of damaged seminiferous tubules $[54.6 \pm 4.3$ and $59.8 \pm 5.6$ (Table 1), respectively].

The BVS subgroups showed increased interstitial space, presence of edema in the interstitial tissues, vasodilatation of interstitial blood vessels, irregularity of germ cell layers, cell nuclei sclerosis, and Sertoli cell degeneration with apparent necrosis in the seminiferous tubules (Figs. 4 and 5). These changes were more pronounced in the BVI subgroups which showed irregular seminiferous tubules with increased lumen width and a marked decrease in the sperm bundles within the lumen (Figs. 4 and 5). However, there seemed to be some regeneration of germinal epithelium in the testicular tissue in several seminiferous tubules in the seven dose (BVS-7 and BVI-7) subgroups (Fig. 6). This recovery was confirmed by the decrease in the percentage of damaged seminiferous tubules [26.7 \pm 2.6 and $29.3 \pm 3.1$ (Table 1)] in the BVS-7 and BVI-7 subgroups, respectively. This indicates that the adverse effect of bee venom on testicular tissue is not permanent.

\section{Discussion}

There are very few published studies that have investigated the testicular toxicity of BVT. Hence, 


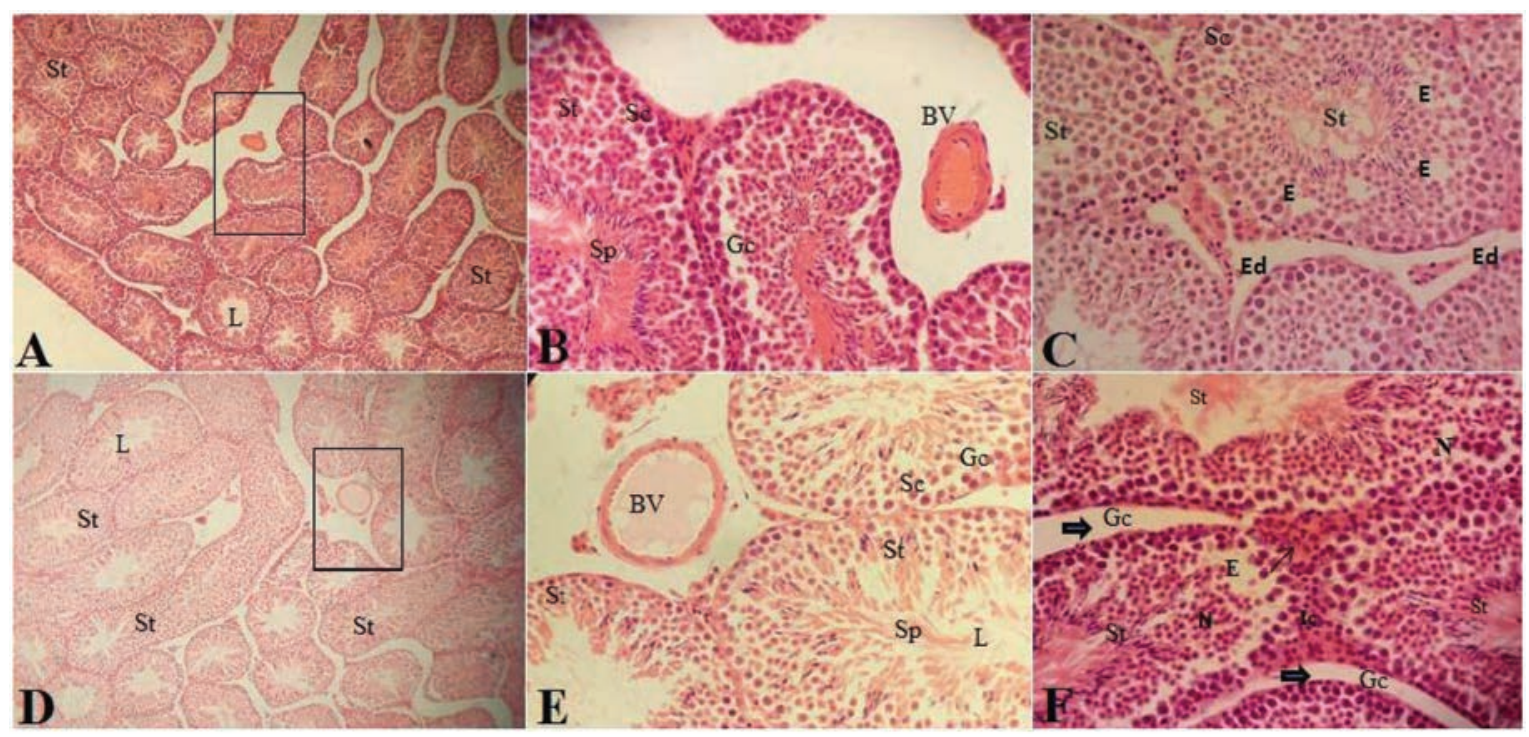

Fig. 5. Histological sections of testes in male mice treated with seven doses of bee venom: BVS-7 subgroup (A, B, and C) and BVI-7 subgroup (D, E, and F) showing an irregular distorted structure of seminiferous tubules, vacuolization of seminiferous tubules, and increased interstitial space (A and D); vasodilation of blood vessels (BV), presence of few spematids/sperms (Sp), and Sertoli cells (Sc) (B and E); edema (Ed), erode (E), necrosis (N), hypertrophic Leydig interstitial cell (Ic) with vacuoles (thin arrow), and germ cell sloughing (Gc) (thick arrows) (C and F) (H\&E) (A and D: $200 \times)(B, C, E$, and F: 400×).

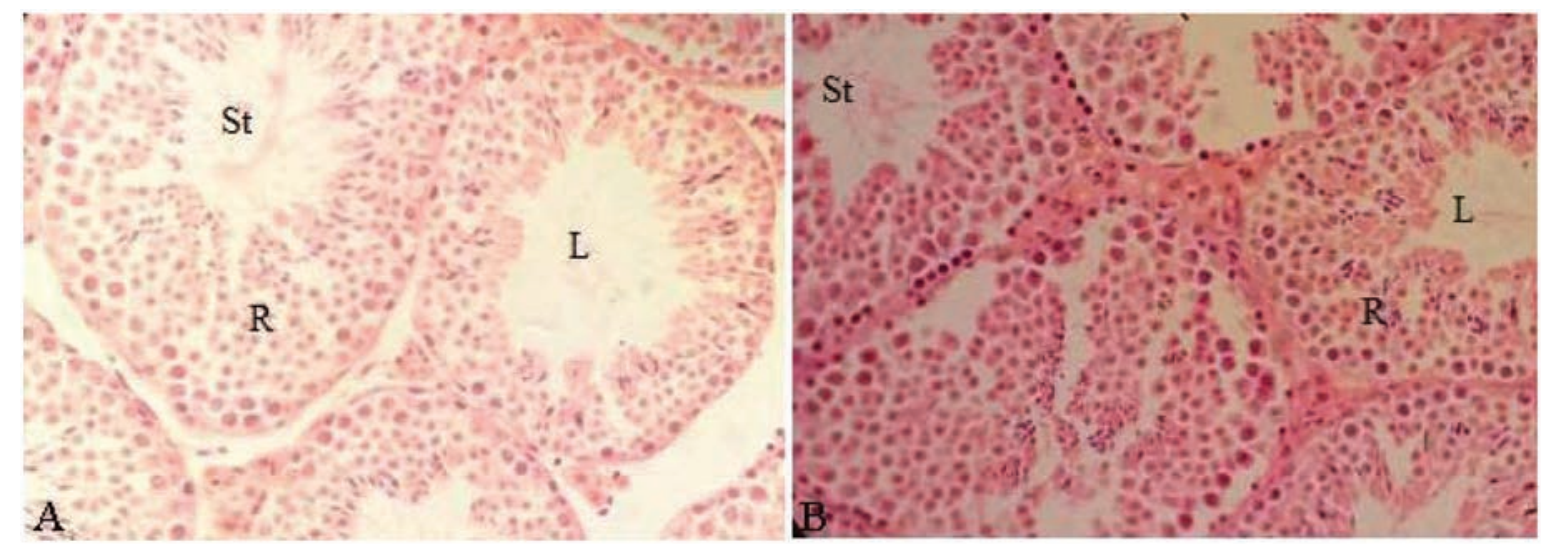

Fig. 6. Histological sections of testes in male mice treated with seven doses of bee venom: BVS-7 subgroup (A) and BVI-7 subgroup (B) showing restoration of normal structure of seminiferous tubules - an indication of recovery (R) (H\&E) (400×).

testicular and reproductive toxicity studies of BVT in men are needed to assess the impact of bee venom exposure on essential male fertility indices which include the measurement of testosterone levels, sperm count, sperm motility, and sperm morphology. In Libya, many infertile men use BVIs for the treatment of infertility by attending CAM clinics; although, to the best of our knowledge, there are no published scientific studies to support or discourage this practice and no information available on the effectiveness of this treatment and safety of patient. Therefore, the assessment of testicular and reproductive toxicity studies of BVIs will have an important implication to infertile couples and public health. For this reason, the present study was conducted to investigate the effect of bee venom on semen quality and testes histology in adult male mice to provide more knowledge on the reproductive toxicity of bee venom, considering the fact that the literature in this regard is very scarce.

The results of this study provide evidence for low semen quality and adverse testicular histological changes in male mice treated with bee venom. The repeated administration of bee venom by sting or injection to adult male mice results in harmful reproductive effects as evidenced by the decrease in serum testosterone levels, reduction in sperm parameters, especially normal sperm morphology, and histological damage to the testes. Low testosterone 
levels, low sperm count, inadequate sperm motility, and abnormal sperm morphology or a combination of these factors have been reported to be major causes of male infertility (Kumar and Singh, 2015; Punab et al., 2017).

The decline in the concentration of testosterone following bee venom treatment indicates harmful changes in the Leydig interstitial cells of testes, which are responsible for testosterone biosynthesis and secretion (Smith and Walker, 2014). Furthermore, the reduction in sperm count could be attributed to the decline in the concentration of testosterone through induction of Leydig cell damage that disrupts testosterone synthesis. Adequate levels of testosterone are needed to maintain normal spermatogenesis (Smith and Walker, 2014) which results in normal sperm count, while decreased sperm motility could be due to DNA damage (Pourmasumi et al., 2017), testicular oxidative stress, and increase in phospholipids peroxidation (Tremellen, 2008). The enzyme phospholipase A2 (PLA2) present in the bee venom interacts specifically with plasma membranes and catalyzes the breakdown of phospholipids within their structure (Lee and Bae, 2016). Therefore, PLA2 breakdowns plasma membranes of sperms and contributes to decreased sperm motility. Escoffier et al. (2010) reported that the PLA2 enzymes present in the snake venom of Oxyuranus scutellatus scutellatus were highly potent inhibitors of sperm motility.

Sperm morphology is under genetic control (Beatty, 1970) involving several autosomal and Y-specific genes. Increases in abnormal sperm morphology are important indicators of genetic damage. Abnormal sperm morphology is usually caused by DNA mutations and chromosomal aberrations that occur during the compaction of DNA in the sperm head (Bruce and Heddle, 1979) that are undergoing spermatozoon differentiation and maturation during the process of spermatogenesis. Bee venom acts in a similar way to other known chemical mutagens by significantly increasing the percentage of abnormal sperm morphology. Therefore, bee venom appears to be a potent mutagenic and genotoxic agent because its greatest harmful effect was exerted on sperm morphology, according to the results of the present study.

Reduction in sperm parameters is consistent with the histopathological analysis of the testicular sections of the testes of mice treated with bee venom that showed significant harmful changes that occurred in the seminiferous tubules, including the detachment of Sertoli cells, sloughing of spermatogonia, increased interstitial space, degenerative changes of the Leydig interstitial cells, and irregular organization of seminiferous tubules with distortion of the testicular structure. However, there seems to be some recovery in the testicular tissue of seminiferous tubules due to the ability of self-renewal (Oatley and Brinster, 2008), indicating that the adverse effect of bee venom on testicular tissue is not permanent.

The histological results of this study are in agreement with the results published by Florea et al. (2017) and Tilinca and Florea (2018), who previously reported similar histopathological changes in testes of bee venom-treated rats which could result in the impairment of spermatogenesis. Florea et al. (2017) found that injecting rats with bee venom resulted in testicular tissue damage, especially the Leydig cells, Sertoli cells, and the germinal epithelium of seminiferous tubules. Tilinca and Florea (2018) investigated the histotoxicity of two major components of bee venom PLA2 and Mlt. They found that PLA2 injection to rats led to the detachment of Sertoli cells from the surrounding germinal epithelium and necrosis, while Mlt injection resulted in degenerative changes of the spermatogenic germinal epithelium. These two studies provided evidence for the damaging effect of bee venom on histoarchitecture of rat testes and conclude that bee venom is a testicular toxic agent (Florea et al., 2017; Tilinca and Florea, 2018). However, previous sperm analyses studies regarding the effect of bee venom on semen quality were not found.

\section{Conclusion}

Assessments of bee venom testicular toxicity studies are very important to safeguard men against any possible adverse effects. This study demonstrated that bee venom (of A. mellifera, order Hymenoptera and family Apidae) is a testicular toxic agent in adult male mice. Therefore, we conclude that bee venom cannot be utilized as a fertility-enhancing agent in infertile males. On the contrary, the results suggest that bee venom has antifertility properties. Bee venom may inhibit reproductive functions in males via disruption of the normal process of spermatogenesis, resulting in the loss of germ cells, decline in sperm concentration, poor sperm motility, abnormal sperm morphology, and low testosterone levels, as well as harmful changes affecting both the histological architecture and structural organization of the testes in the bee venom-treated mice. All of the aforementioned parameters have been reported to be major causes of male infertility. Bee venom toxicity mechanisms appears to be cytotoxic, genotoxic, and anti-androgenic. The results of this study are very significant and have clinical relevance; taking into account that there are only two published studies on bee venom reproductive toxicity, further studies assessing reproductive parameters, semen quality, and fertility for men receiving BVT are needed. Moreover, infertility problems among beekeepers should also be investigated because perhaps the repeated exposure to BVSs during the handling of bees is the cause of infertility. There is a desperate need for educating CAM healthcare practitioners and infertile couples about the harmful effects of BVT on reproductive status. 


\section{Acknowledgments}

The authors gratefully acknowledge the facilities provided by the Department of Zoology Faculty of Science, University of Tripoli, Tripoli, Libya. They also thank Al-Hart CAM clinic in Tripoli for providing the BVT regime in infertile men and for the bee venom powder gift.

\section{Conflict of interest}

The authors declare that there is no conflict of interest. Authors' contribution

SOR, SAA, and NSS planed the experimental design of this study and the measurements of semen quality parameters. SOR conducted the literature review, drafting, revision, and wrote the final manuscript. SAA prepared the histology slides and comments. NSS provided the honeybees and bee venom powder and conducted the statistical analysis. All authors read and approved the final manuscript.

\section{References}

Agarwal, A., Mulgund, A., Hamada, A. and Chyatte, M.R. 2015. A unique view on male infertility around the globe. Reprod. Biol. Endocrinol. 13(1), 37.

Ali, M.A.M. 2012. Studies on Bee Venom and its medical uses. Int. J. Advanc. Res. Technol. 1(2), 69-83.

Ashur, S.T., Shah, S.A., Bosseri, S. and Shamsuddin, K. 2017. Use of traditional medicine among type 2 diabetic Libyans. Eastern Mediterr. Health J. 23(5), 375-382.

Aufschnaiter, A., Kohler, V., Khalifa, S., Abd ElWahed, A., Du, M., El-Seedi, H. and Büttner, S. 2020. Apitoxin and its components against cancer, neurodegeneration and rheumatoid arthritis: limitations and possibilities. Toxins. 12, 66.

Auger, J., Kunstmann, J.M., Czyglik, E. and Jouanet, P. 1995. Decline in semen quality among fertile men in Paris during the past 20 years. N. Engl. J. Med. $332,281-285$.

Bardaweel, S.K., Shehadeh, M., Suaifan, G.A. and Kilani, M.Z. 2013. Complementary and alternative medicine utilization by a sample of infertile couples in Jordan for infertility treatment: clinics-based survey. BMC Complement. Altern. Med. 13, 35.

Baskaran, S., Agarwal1, A., Selvam, M.K.P., Finelli, R., Robert, K.A., Iovine, C., Pushparaj, P.N., Samanta, L., Harlev, A. and Henkel, R. 2019. Tracking research trends and hotspots in sperm DNA fragmentation testing for the evaluation of male infertility: a scientometric analysis. Reprod. Biol. Endocrinol. 17, 110.

Beatty, R.A. 1970. The genetics of the mammalian gamete. Biol. Rev. Camb. Philos. Soc. 45(1), 73-119.

Bruce, W.R. and Heddle, J.A. 1979. The mutagenic activity of 61 agents as determined by the micronucleus, Salmonella and sperm abnormality assays. Can. J. Genet. Cytol. 21, 319-334.
Carlsen, E., Giwercman, A., Keiding, N. and Skakkebaek, N.E. 1992. Evidence for decreasing quality of semen during past 50 years. BMJ. 305, 609-613.

de Kretser, D.M. 1997. Male infertility. Lancet 349, 787-790.

Dukhovny, D., Hwang, S.S., Gopal, D., Cabral, H., Missmer, S., Diop, H., Declercq, E. and Stern, J.E. 2018. Length of stay and cost of birth hospitalization: effects of subfertility and ART. J. Perinatol. 38(11), 1457-1465.

El-Bassiony, M.N., Mahfouz, H.M., Hussein, A.S., ElHamamy, M.M., Abdel Daim, M.M. and Bufo, S.A. 2016. Effect of honey Bee Venom on cancer in rats model. J. Entomol. 13, 72-83.

Eldib, A. and Tashani, O.A. 2018. Infertility in the Middle East and North Africa Region: a systematic review with meta-analysis of prevalence surveys. Libyan J. Med. Sci. 2, 37-44.

El-Mokasabi, F. 2014. The state of the art of traditional herbal medicine in the eastern mediterranean coastal region of Libya. Middle-East J. Sci. Res. 21, 575-582.

Escoffier, J., Couvet, M., de Pomyers, H., Ray, P.F., Sève, M., Lambeau, G., De Waard, M. and Arnoult, C. 2010. Snake venoms as a source of compounds modulating sperm physiology: secreted phospholipases A2 from oxyuranus scutellatus scutellatus impact sperm motility, acrosome reaction and in vitro fertilization in mice. Biochimie. 92(7), 826-836.

Fiscor, G. and Ginsberg, L.C. 1980. The effect of hydroxyurea and mitomycin $\mathrm{C}$ on sperm motility in mice. Mutat. Res. 70, 383-387.

Florea, A., Puica, C., Hamed, S., Tilinca, M. and Matei, H. 2017. Histopathological and ultrastructural changes experimentally induced by bee venom in seminiferous epithelium via structural-functional alteration of Sertoli cells. Micron. 102, 1 e14.

Frass, M., Strassl, R.P., Friehs, H., Müllner, M., Kundi, M. and Kaye, A.D. 2012. Use and acceptance of complementary and alternative medicine among the general population and medical personnel: a systematic review. Ochsner J. 12(1), 45-56.

Ghazeeri, G.S., Awwad, J.T., Alameddinem, M., Younes, Z.M. and Naja, F. 2012. Prevalence and determinants of complementary and alternative medicine use among infertile patients in Lebanon: a cross sectional study. BMC Complement. Altern. Med. 12(1), 129.

Han, S.M., Kim, J.M., Hong, I.P., Woo, S.O., Kim, S.G., Jang, H.R. and Pak, S.C. 2016. Antibacterial activity and antibiotic-enhancing effects of honeybee Venom against methicillin-resistant staphylococcus aureus. Molecules. 21, 79.

Hwang, J.H., Kim, Y.Y., Bin, I.H. and Han, D. 2019. Complementary and alternative medicine use among infertile women attending infertility specialty clinics 
in South Korea: does perceived severity matter? BMC Complement. Altern. Med. 19, 301.

Inhorn, M.C. and Patrizio, P. 2015. Infertility around the globe: new thinking on gender, reproductive technologies and global movements in the $21 \mathrm{st}$ century. Hum. Reprod. Update 21(4), 411-426.

Irvine, D. S. 1998. Epidemiology and aetiology of male infertility. Hum. Reprod. 13(Suppl. 1), 33-44.

Kim, H., Park, S.-Y. and Lee, G. 2019. Potential therapeutic applications of Bee Venom on skin disease and its mechanisms: a literature review. Toxins 11(7), 374.

Kissin, D.M., Boulet, S.L., Jamieson, D.J. and Assisted Reproductive Technology Surveillance and Research Team. 2016. Fertility treatments in the United States: improving access and outcomes. Obstet. Gynecol. 128(2), 387-390.

Kotb, F.T. 1985. Medicinal plants in Libya. Beirut, Lebanon: Arab Encyclopedia House.

Kumar, N. and Singh, A.K. 2015. Trends of male factor infertility, an important cause of infertility: a review of literature. J. Hum. Reprod. Sci. 8, 191-196.

Lee, G. and Bae, H. 2016. Bee Venom phospholipase A2: yesterday's enemy becomes today's friend. Toxins 8(2), 48.

Li, D., Lee, Y., Kim, W., Lee, K., Bae, H. and Kim, S.K. 2015. Analgesic effects of Bee Venom derived phospholipase A2 in a mouse model of oxaliplatininduced neuroptic pain. Toxins 7(7), 2422-2434.

Miner, S.A., Robins, S., Zhu, Y.J., Keeren, K., Gu, V., Read, S.C. and Zelkowitz, P. 2018. Evidence for the use of complementary and alternative medicines during fertility treatment: a scoping review. BMC Complement. Altern. Med. 18(1), 158.

NIH (National Institute of Health). 1985. Principles of laboratory animal care. Bethesda, MD, National Institute of Health, pp: 1-96.

Oatley, J.M. and Brinster, R.L. 2008. Regulation of spermatogonial stem cell self-renewal in mammals. Annu. Rev. Cell Dev. Biol. 24, 263-286.

Ombelet, W. and Onofre, J. 2019. IVF in Africa: what is it all about? Facts Views Vis. Obgyn. 11(1), 65-76.

O'Reilly, E., Sevigny, M., Sabarre, K.A. and Phillips, K.P. 2014. Perspectives of complementary and alternative medicine (CAM) practitioners in the support and treatment of infertility. BMC Complement. Altern. Med. 14, 394.

Park, J., Kwon, O., An, H.J. and Park, K.K. 2018. Antifungal effects of Bee Venom components on trichophyton rubrum: a novel approach of Bee Venom study for possible emerging antifungal agent. Ann. Dermatol. 30, 202-210.

Pourmasumi, S., Sabeti, P., Rahiminia, T., Mangoli, E., Tabibnejad, N. and Talebi, A.R. 2017. The etiologies of DNA abnormalities in male infertility: an assessment and review. Int. J. Reprod. Biomed. 15(6), 331-344.
Punab, M., Poolamets, O., Paju, P., Vihljajev, V., Pomm, K., Ladva, R., Korrovits, P. and Laan, M. 2017. Causes of male infertility: a 9-year prospective monocentre study on 1737 patients with reduced total sperm counts. Hum. Reprod. 32(1), 18-31.

Read, S.C., Carrier, M., Whitley, R., Gold, I., Tulandi, T. and Zelkowitz, P. 2014. Complementary and alternative medicine use in infertility: cultural and religious influences in a multicultural canadian setting. J. Altern. Complement. Med. 20(9), 686-692.

Sadeghi, M.Z. 2020. A new perspective for the future of male infertility treatment and research. J. Reprod. Infertil. 21(1), 1-2.

Schumacher, M.J., Tveten, M.S. and Egen, N.B. 1994. Rate and quantity of delivery of Venom from honeybee stings. J. Allergy Clin. Immunol. 93, 831-835.

Sengupta, P., Borges, E., Dutta, S. and KrajewskaKulak, E. 2018. Decline in sperm count in European men during the past 50 years. Hum. Exp. Toxicol. 37(3), 247-255.

Sengupta, P., Nwagha, U., Dutta, S., Krajewska-Kulak, E. and Izuka, E. 2017. Evidence for decreasing sperm count in African population from 1965 to 2015. Afr. Health Sci. 17(2), 418-427.

Smith, J.F., Eisenberg, M.L., Millstein, S.G., Nachtigall, R.D., Shindel, A.W., Wing, H., Cedars, M., Pasch, L., Katz, P.P. and Group IOPP. 2010. The use of complementary and alternative fertility treatment in couples seeking fertility care: data from a prospective cohort in the United States. Fertil. Steril. 93(7), 2169-2174.

Smith, L.B. and Walker, W.H. 2014. The regulation of spermatogenesis by androgens. Semin. Cell Dev. Biol. 30, 2-13.

Sun, H., Gong, T., Jiang, Y., Zhang, S., Zhao, Y. and Wu, Q. 2019. Global, regional, and national prevalence and disability-adjusted life-years for infertility in 195 countries and territories, 1990-2017: results from a global burden of disease study, 2017. Aging 11(23), 10952-10991.

Teka, I.A. 2018. Male infertility in Libya; evidence, causes and diagnosis. Special issue for the 2nd Annual Conference on Theories and Applications of Basic and Biosciences. September, 1st. Misurata University, Misurata, Libya.

Tilinca, M. and Florea, A. 2018. Ultrastructural analysis of early toxic effects produced by Bee Venom phospholipase A2 and melittin in Sertoli cells in rats. Toxicon. 141, 94-103.

Tremellen, K. 2008. Oxidative stress and male infertility - a clinical perspective. Hum. Reprod. Update 14, 243-258.

Trivedi, P.P., Kushwaha, S., Tripathi, D.N. and Jena, G.B. 2010. Evaluation of male germ cell toxicity in rats: correlation between sperm head morphology 
and sperm comet assay. Mutat. Res. 703(2), $115-121$.

Uddin, M.B., Lee, B.H., Nikapitiya, C., Kim, J.H., Kim, T.H., Lee, H.C., Kim, C.G., Lee, J.S. and Kim, C.J. 2016. Inhibitory effects of Bee Venom and its components against viruses in vitro and in vivo. J. Microbiol. 54, 853-866.

Wehbe, R., Frangieh, J., Rima, M., El Obeid, D., Sabatier, J.M. and Fajloun, Z. 2019. Bee Venom: overview of main compounds and bioactivities for therapeutic Interests. Molecules 24(16), 2997.

WHO. 2014. Sexual and reproductive health: infertility is a global public health issue. Geneva, Switzerland World Health Organization. Available via http:// www.who.int/reproductivehealth/topics/infertility/ perspective/en/

WHO. 2015. Infertility. Geneva, Switzerland World Health Organization. Available via http://www. who.int/topics/infertility/en/

Ye, M., Chung, H.S., Lee, C., Yoon, M.S., Yu, A.R., Kim, J.S., Hwang, D.S., Shim, I. and Bae, H. 2016. Neuroprotective effects of Bee Venom phospholipase A2 in the 3xTg AD mouse model of Alzheimer's disease. J. Neuroinflamm. 13, 10.
Yokoi, K., Uthus, E.O. and Nielsen, F.H. 2003. Nickel deficiency diminishes sperm quantity and movement in rats. Biol. Trace Elem. Res. 93, $141-154$

Yu, A.R., Kim, J.J., Park, G.S., Oh, S.M., Han, C.S. and Lee, M.Y. 2012. Biochemistry: the antifungal activity of Bee Venom against dermatophytes. J. Appl. Biol. Chem. 55, 7-11.

Zegers-Hochschild, F., Adamson, G.D., de Mouzon, J., Ishihara, O., Mansour, R., Nygren, K., Sullivan, E. and Vanderpoel, S. 2009. International Committee for Monitoring Assisted Reproductive Technology (ICMART) and the World Health Organization (WHO) revised glossary of ART terminology. Fertil. Steril. 92, 1520-1524.

Zhang, S., Liu, Y., Ye, Y., Wang, X.R., Lin, L.T., Xiao, L.Y., Zhou, P., Shi, G.X. and Liu, C.Z. 2018. Bee Venom therapy: potential mechanisms and therapeutic applications. Toxicon. 148, 64-73.

Zolfagharian, H., Mohajeri, M. and Babaie, M. 2016. Bee Venom (Apis mellifera) an effective potential alternative to gentamicin for specific bacteria strains: bee venom an effective potential for bacteria. J. Pharmacopunct. 19, 225-230. 